\title{
THE IMPACT OF HEALTH INFORMATION AVAILABLE THROUGH INTERNET ON DOCTOR-PATIENT RELATIONSHIP: A DOCTOR'S PERSPECTIVE
}

\section{Dr. Dolli S. Aasani* \\ Dr. Jayesh Kathiria}

Assistant Professor In Pharmacology Department At Shantabaa Medical College, Amreli (Gujarat). *Corresponding Author

Assistant professor in pharmacology department at Shantabaa Medical College, Amreli.

\section{Dr. Mohit Chauhan}

Senior resident in general surgery department at Shantabaa Medical College, Amreli.

\section{ABSTRACT INTRODUCTION: The World-Wide-Web (WWW) or internet has become an important source of} information including medical information globally. India stands second in the world with approximately 500 million internet users. Worldwide, about $4.5 \%$ of all internet searches are for health-related information and more than 70 , 000 websites disseminate health information. Widespread use of internet as a source of health information has an effect on health-related knowledge, attitude and practices of general population as well as doctor-patient relationship. OBJECTIVE: To assess the impact of health information available through internet on doctor-patient relationship from the doctor's perspective. Methods: A web based study was conducted among the clinical doctors for the duration of 2 months. 16 questionnaires were prepared by authors and pre-validated by pilot study and expert's opinion. Written informed consent from each 31 doctors participated in the study had taken. RESULT: $87 \%$ doctors agree that patient who had done internet search before the doctor's visit, takes more consultation time. $71 \%$ doctors believes that it is difficult to treat internet user patient because of distrustful behaviour and they suggest new investigations or ask for super-specialist's opinion. $90 \%$ doctors agree that distrustful patients misuses the internet health information to test doctor's knowledge. $77 \%$ doctors believes that in spite of google search patients still have same faith on doctor. CONCLUSION: The impact of health information available through internet on doctor-patient relationship is both positive and negative and they perceive the overall effects on doctor-patient relationship as neutral.

\section{KEYWORDS : Internet, Health Information, Doctor-patient Relationship, Knowledge}

\section{INTRODUCTION}

In the 'pre-internet era' medical information was only available in textbooks, journals or from doctors. ${ }^{1}$ The World-Wide-Web (WWW) or internet has become an important source of information including medical information globally. ${ }^{2}$ India stands second in the world with approximately 500 million internet users. ${ }^{3}$ Worldwide, about $4.5 \%$ of all internet searches are for health-related information and more than 70 , 000 websites disseminate health information. ${ }^{4}$ Many patients or their relatives, especially in an urban area have an easy access to the internet and routinely make use of it to obtain medical information.

The internet is an important tool in searching for information. Internet searching for health-related information has been shown to have positive effects on the frequency of visits to health professionals for those who seek such information compared to those who did not. Health-related information seeking affects individuals' demands for health care services and increases health care utilization. However, many people can obtain and disseminate information via the internet, regardless of whether health-related information is correct.

Many concerns about potential disadvantages of online patient resources have been presented, however. Such concerns and indeed objections generally can be classified into one of the following areas:

- Reduced physician influence as the patient may no longer view the physician as the ultimate healthcare authority, perhaps even bypassing the patient-physician relationship in favour of self-treatment

- Increased time and cost burdens on physicians and the medical system that result from patient questions and requests for inappropriate testing or treatment.

Very few studies have been done on this aspect. Hence this study had been planned to see perception of doctors about patients who had medical information by internet search. In this era of information technology, in view of changing scenario of doctor-patient relationship it is prudent to do this type of study. Result of study may be helpful for redesigning the approach of clinician towards patients.

The primary objective of the study was to assess the impact of health information available through internet on doctorpatient relationship from the doctor's perspective.

\section{Material and Methodology}

A cross sectional, web based, qualitative study was conducted among the clinical doctors attached with Shantabaa Medical College and General Hospital (SMCGH), Amreli and private doctor's practicing at Amreli city for the duration of 2 months (May-June 2020). Total 16 questions based study conducted through goggle form.

Inclusion criteria:

- Doctor with clinical practices

- Doctors willing to participate in the study and given written informed consent were only included in the study

- Exclusion criteria:

- Doctors concerned with non-clinical branches

- Peripheral doctors working at Primary Health Care Centre (PHC) and Community Health Care Centres (CHC), Urben Health care Centrers (UHC) etc.

- Doctors not given written informed consent

Questionnaires were prepared by authors and pre-validated by pilot study and expert's opinion. Study participants were surveyed using a google form questionnaire comprises 16 statements rated on likert scale.

Likert scaling is a bipolar scaling method, measuring either a positive or a negative response to a statement. ${ }^{7}$ A score of more or less than three indicate a positive or negative response to a statement respectively. A score of three indicate neutral response. The format of a typical five level likert item is: strongly disagree (strongly unfavourable to the concept), disagree (somewhat unfavourable to the concept), neither agrees nor disagrees (undecided), agree (somewhat 
favourable to the concept), strongly agree (strongly favourable to the concept).

Written informed consent from each doctor participating in the study had taken. Total 31 doctors doing clinical practice either in government sector or private practitioner had participated in the study.

\section{RESULT:}

Total 31 doctors has responded to web based 16 closed-end questions. Out of 31 doctors $55 \%$ are specialist in their branch and $52 \%$ doctors had more than 3 years work experience. Majority of doctors (61\%) working on government sectors.

From the chart-l we can see that $64.5 \%$ doctors opined that the use of internet by patient and their relatives has affected doctor-patient relationship and also $64.5 \%$ doctors believe that with usage of internet patient's confidence on doctor is doughtful or decreased. Most of doctors strongly agree (38.7 $\%) /$ Agree $(48.4 \%)$ that patient who had done internet search before the doctor's visit, takes more consultation time than average and $71 \%$ opined that patients suggest new investigations and ask for super-specialist's opinion. According to $61.3 \%$ doctors opinion most of patients believe health information available on internet as a reliable source of information. The study suggests $52 \%$ doctors agree that internet search misguide the patients for self-treatment or wrong diagnosis and $90 \%$ doctors agree to statement that distrustful patients misuses the internet health information to test doctor's knowledge. $71 \%$ doctors believes that it is difficult to treat internet user patient because of distrustful behaviour. In the study $42 \%$ doctor agree and $39 \%$ doctors disagree to the statement that lack of satisfaction with doctor's consultation may be reason for google search and also different opinion for statement that poor socio-economical status of patient may be reason for the google search as alternative to doctor's visit. $49 \%$ clinician disagree and $10 \%$ strongly disagree to statement that because of widespread internet users, the average number of patients in Out-Patient Department (OPD) has decreased. According to study $51.6 \%$ doctors agree and $6.5 \%$ strongly agree that now a days many doctors are using internet for e-prescriptions and most of them (58.1\%) believe that wisely used internet can be a good source of updating medical knowledge both for doctor and patients. During pandemics like COVID-19 (Corona Virus Disease-2019) $60 \%$ clinician agree that internet is very useful tool for diagnosis and treatment of patients. Different opinion to statement that sometimes patient come with a new medical information which may be source of new medical information for a doctor. $77 \%$ doctors believes that in spite of google search patients still have same faith on doctor.

Table 1 shows study questionrries and stastical analysis done with mean and Standard Deviation (SD). From this table 1 we can conclude that for Q9,Q10,Q11 and Q15 mean is less than 3 and SD $>1$ suggest that doctors strongly disagree to that questions/statements.

Table 1: Study questionarries with mean and standard deviation

\begin{tabular}{|l|l|l|l|}
\hline Study Questions & N & Mean & $\begin{array}{l}\text { Standard } \\
\text { Deviation }\end{array}$ \\
\hline $\begin{array}{l}\text { Q1. The use of internet by patient and } \\
\text { their relatives has affected doctor- } \\
\text { patient relationship }\end{array}$ & 31 & 4.2 & 0.73 \\
\hline $\begin{array}{l}\text { Q2. With usage of internet patient's } \\
\text { confidence on doctor is doughtful or } \\
\text { decreased }\end{array}$ & 31 & 3.9 & 0.75 \\
\hline $\begin{array}{l}\text { Q3. Patient who had done internet } \\
\text { search before the doctor's visit, takes } \\
\text { more consultation time than average }\end{array}$ & 31 & 4.2 & 0.76 \\
\hline Q4. Internet user patient suggest new & 31 & 4.2 & 0.50 \\
\hline
\end{tabular}

investigations and ask for superspecialist's opinion.

Q5. Most of patients believe health information available on internet as a reliable source of information

Q6. Internet search misguide the patients for self-treatment or wrong diagnosis

Q7. Distrustful patients misuses the internet health information to test doctor's knowledge

Q8. It is difficult to treat internet user patient because of distrustful behaviour

Q9. Lack of satisfaction with doctor's consultation may be reason for google search.

Q10. Poor socio-economical status of patient may be reason for the google search as alternative to doctor's visit

Q11. Because of widespread internet users, the average number of patients in OPD has decreased

Q12. Now a days many doctors are using internet for e-prescriptions Q13. Wisely used internet can be a good source of updating medical knowledge both for doctor and patients.

Q14. During pandemics like COVID19 , internet is very useful tool for diagnosis and treatment of patients. Q15. Sometimes patient come with $\alpha$ new medical information which may be source of new medical information for a doctor.

Q16. In spite of google search patients still have same faith on doctor

\section{DISCUSSION}

According to this study $64.5 \%$ doctors opined that internet usage has affected doctor-patient relationship as compared to $87 \%$ in Banginwar S et al study ${ }^{8}$ and in Oliveira J.F. study $56.9 \%$ says positive impact, $27.6 \%$ interfered with and $15.5 \%$ believed that internet had negative impact on doctor-patient relationship.

$87.6 \%$ doctors agreed that internet user patients takes more consultation time than average as compared to $95.2 \%$ in Banginwar S et al study ${ }^{8}$ while in Murry E et al study ${ }^{10} 38 \%$ physician believed that the effect of the patient bringing information has harmed their consultation time. Oliveira J.F. study ${ }^{9}$ suggests $46.6 \%$ of respondents opined that patient who attended after reading a lot of information on internet usually made their appointments last longer.

Banginwar $\mathrm{S}$ et al study ${ }^{8}$ detected $90.7 \%$ internet savvy patients suggest new investigations and ask for super specialist's opinion as compared to $71 \%$ in our study.

This study suggests $90 \%$ doctors agree that distrustful patients misuses the internet to test doctor's knowledge while $n$ Banginwar $\mathrm{S}$ et al study it is $84.8 \%$.

Oliveira J.F. study ${ }^{9}$ suggests $42.2 \%$ of doctors stated that they had patients arriving with information from internet, which was new to even the professionals themselves while in our study it is $38.7 \%$.

$58.1 \%$ doctors believed that wisely used internet can be a good source to update medical knowledge while in Murry E et 
al study ${ }^{10} 61 \%$ respondents accepted that they use internet in their practice.

\section{CONCLUSION}

The impact of health information available through internet on doctor-patient relationship is both positive and negative and they perceive the overall effects on doctor-patient relationship as neutral. Majority of doctors believes that in spite of google search patients still have same faith on doctor and internet usage had not any negative effect on the average number of patients in OPD. During the pandemic like COVID19 infection, judicial use of internet can be very helpful.

In this digital world, rather than the physicians, internet is the first source of information for many people. ${ }^{11}$ Health information available on internet can be act as a doubleedged sword. Wisely used internet can be a good source to update knowledge for both doctors and patients while incorrect use of it may lead to misguide the patients and their relatives.

\section{Chart 1: Overview of doctor's responses to the study quetionarries}

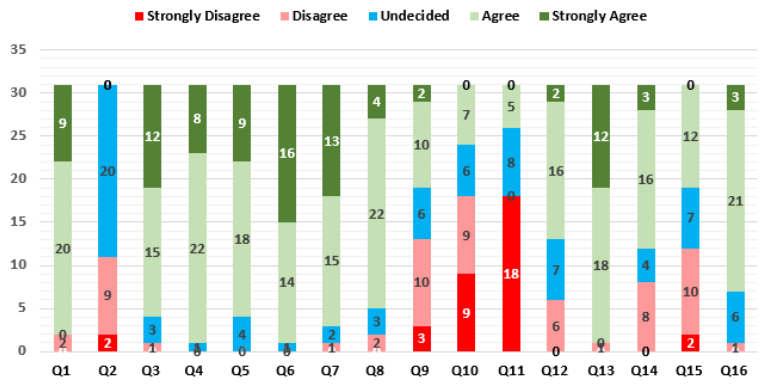

${ }^{*}$ Q1-Q16 suggest our study questions which is mentioned in detail in Table 1.

\section{REFERENCES}

1. Marcinkiewicz M. Mahboobi H. The Impact of the internet on the DoctorPatient Relationship. AMJ 2009, 1, 5, 1-6. Doi 10.4066/AMJ.2009.69

2. Kothari M, Moolani S. Reliability of google for obtaining medical information. Indian J Opthalmol. 2015;63(3):267-9.

3. Maheshwari S K, Sharma P. Internet Addiction: A Growing Concern In India. Indian Journal of Psychiatric Nursing 15(1) Jan - June 2018.

4. Renganathan L, Ray S, Nagpal D. Use of internet for accessing healthcare information among patients in an outpatient department of a Tertiary Care Center. J Mar Med Soc 2017; 19:15-7.

5. Mimura W, Akazawa M The Association Between Internet Searches and Moisturizer Prescription in Japan: Retrospective Observational Study JMIR Public Health Surveill 2019;5(4):el3212Rensis L. A technique for the measurement of attitudes. Arch Psychol. 1932;140:1-55.

6. Iverson SA, Howard KB, Pennery BK. Impact of internet use on health-related behaviours and the patient-Physician relationship: A survey- based study and review. J Am Osteopath Assoc. 2008; 108:699-711.

7. Rensis L. A technique for the measurement of attitudes. Arch Psychol. 1932;140:1-55.

8. Banginwar S, Amruta DV, Archana B, Jaideep N, Rupesh B. Impact of internet on doctor-patient relationship. Int J Basic Clin Pharmacol 2020;9:731-5.

9. Oliveira JF. The effect of the internet on the patient-doctor relationship in a hospital in the city of Sao Paulo. Journal of information system and Tecnology management. May2014;1 1(2):327-44.

10. Murry E, Lo B, Pollack L, Donelan K, Catania J, Lee K, Zapert K, Turner R. The impact of health information on the internet on the health care and the physician-patient relationship: National U.S. survey among the 1,050 physicians.J Med Internet Res. Jul-Sep; 5(3):el7

11. Tonsaker T, Bartlett G, Trpkov C, Health information on the Internet Gold mine or minefield? Canadian Family Physician - Le Médecin de famille canadien.: May 2014;60:pg419. 